\title{
Affects and Cognition in a Social theory of Unconscious Processes
}

\author{
by Ralph Stacey \\ University of Hertfordshire
}

June 2003

Published in Group Analysis 2005.

This paper argues that affects and cognition cannot be separated in human consciousness and that human consciousness is fundamentally a social phenomenon. This contention is based on a number of arguments. First, research into brain functioning indicates that those centres of the brain that deal with emotion also deal with the capacity to select rational and moral actions. Second, is the argument that attachment and separation behaviours, that is, social acts, are essential for the human body's capacity to regulate itself. Next, the paper reviews G. H. Mead's theory of symbolic interactionism, according to which human consciousness and self consciousness arise in social acts so that the individual is social through and through. The notion of "the" unconscious is then explored. It is argued that this is a fundamentally individualistic notion of what is unconscious in human action and as such is incompatible with the contention that human consciousness is a social process. Suggestions are made for thinking of what is unconscious in terms of social processes. The paper concludes with a section on how one might think abut disturbance and pathology from the perspective of complex responsive processes.

Key words: social body, consciousness, unconscious processes, power, communication, complex responsive processes, disturbance, pathology.

Psychoanalytic theories of mental functioning have mostly been developed from the practice of analysis and therapy where the main focus of attention is on disturbances of one kind or another to that mental functioning. For example, Freud's theories were heavily influenced by his patient group of hysterics, Klein's by her patient group of disturbed children, Bion's by his patient group of psychotics, Kohut's by his encounters with narcissistic personalities, and so on. Views of normal mental functioning tended to be inferred from this starting point of disturbance and pathology. Another striking feature of psychoanalytic theory, for me, is the major developments it presents in understanding the unconscious aspects of mental life and the relative neglect of that which is conscious. This paper seeks to move in the opposite direction to psychoanalytic theorising by starting with theories of 'normal' mental functioning. Explanations of disturbance and pathology are then to be understood as some kind of divergence from this 'normal' functioning. This paper also seeks to focus on the development of a theory of consciousness as the basis for understanding that which is unconscious (Stacey 2003).

If the starting point is to be that which is 'normal', then it is necessary to provide a definition of 'normal'. By normal, I mean ordinary, everyday relating between people that is good enough. Relating is good enough when people are able to go on together, 
cooperating and competing with each other, so that they accomplish, reasonably effectively, what they need to do in order to lead an ordinary life with some acceptable sense of well being. Central to such an acceptable sense of well being is the recognition of oneself as a person by those whom one recognises as persons. In other words, well being relates to a reasonably secure sense of individual ' $\mathrm{I}$ ' identity, which Elias and Scotson (1994/19965) argued is always inseparable from senses of collective 'We' identities. My understanding of 'normal', therefore, immediately relates to social interaction. It expresses Foulkes' (1948) claim that it is an abstraction to separate the individual and the social. In this regard, Foulkes was influenced by Elias (1939/2000), for whom the individual is the singular, and the social is the plural, of the same phenomenon, namely, interdependent people.

Normal human relating can only occur through reasonably satisfactory communicative interaction between conscious / self conscious bodies. This paper draws on G.H. Mead's (1934) development of Hegel's philosophy on the social nature of human knowing to provide a theory of consciousness and self consciousness arising in communicative interaction. In relating to each other, people simultaneously enable and constrain each other. This is a matter of power (Elias, 1939/2000). Power relating is thus as central an aspect of human interaction as communication. Combining these aspects of communication and power with insights from the complexity sciences about the selforganising, emergent nature of interaction leads to a theory of individual and groups, which colleagues and I have called a theory of complex responsive processes (Stacey, Griffin \& Shaw, 2000; Stacey, 2001; Stacey, 2003).

Starting from the position that consciousness / self-consciousness is a social phenomenon leads to the proposition that unconsciousness too must be a social phenomenon. This paper will explore the social nature of unconscious processes and argue that consciousness and unconsciousness are inseparable, completely intertwined aspects of the same processes of human communicative interacting and power relating.

Finally, the paper will consider the nature of disturbance and pathology. For Foulkes (1948, 1964), disturbance and pathology were the same as failures in communication, or disturbance in the relating between people in a group, which tended to be located in an individual who was then labelled 'neurotic' or psychotic'. This paper will point to how such failures of communicating can be understood from the perspective of complex responsive processes.

The first step in the argument, however, is to establish the social nature of human bodies and look at the reasons why cognition and affect cannot be separated in our understanding of the conscious / unconscious interaction of human bodies.

\section{Social Bodies}

The human brain is highly undifferentiated at birth and it is experience that primarily shapes connections in the brain, not genetically pre-planned hard-wiring. Schore (1994) 
has explored research leading to the conclusion that child-caregiver interaction shapes the development of the brain. Furthermore, this shaping and re-shaping by experience continues throughout life. In other words, the human brain is highly plastic (Siegel, 1999). Throughout life, new brain connections are made and old ones pruned. It seems that traumatic experiences and emotional disturbances result in over pruning of brain connections, so affecting subsequent experience. Humans, then, have social brains in that they are primarily formed by social experience. Furthermore, it seems that social experience is essential to the ongoing regulation of the body.

Smith and Stevens (Smith \& Stevens, 1999; Smith, 2001) quote a number of researchers (McGuire et al, 1984; Reite \& Field, 1985, Wise \& Rompre, 1989) who have identified a specific group of neurochemicals and receptors in the brain identified as the opioid system. Opioids are morphine-like and an example is the endorphins released by exercise. It is these mechanisms that give rise to physiological changes associated with feelings of comfort, control and calm. Other neurochemicals, however, constitute the arousal system, which consists of hormones, such as norepinephrine, which produce feelings of excitement, fear and anxiety. Taken together, the opioid and arousal systems seem to constitute an interlinked system: in part, opioids produce a soothing effect through inhibiting norepinephrine and vice versa, so that increases in one mechanism produce reductions in the other. The link between opioid and arousal systems, therefore, provides a physiological process of body regulation. Too much opioid leads to passive, inactive bodies, which must be countered by norepinephrine release. But too much norepinephrine leads to hyperactivity and this must be countered by opioid release. A healthily functioning body, therefore, requires an effective process of regulating opioid and norepinephrine releases in an inevitably cyclical process.

Smith and Stevens then point to research indicating that the human body cannot accomplish this chemical regulation in isolation from other bodies. Researchers have shown that attachment behaviour triggers opioid release while separation behaviour triggers norepinephrine release. The human body, therefore, requires attachment to, and separation from, other bodies in order to regulate itself. Brain processes and social processes are thus interlinked in the form of what Smith calls a hyperstructure. Taken together, the opioid and arousal systems seem to constitute a system mediating social attachment and distress and social attachment and distress mediate changes in the neurochemical system. The body requires, and will therefore provoke, attachment and separation actions for the purpose of physiological regulation and it is in this sense that we can say that the human body is a social body. How particular patterns of interaction materialize in the operation of the hyperstructure depends upon human interaction in the living present as that interaction reconstructs the past and perpetually creates the future. Social behaviour is physiologically constrained into certain patterns and we depend upon social life to maintain requisite physiological states. Evolution has produced humans whose physiological states can only be maintained by certain kinds of social behaviour

The connection between neurochemical systems and social interaction changes as people mature and increasingly develop the capacity to modulate their feelings of anxiety apart from each other. Affect regulation can then be carried out more within the body, with less 
reliance on social interaction but never without it altogether. Behaviours to do with attachment and separation increase and diversify with psychological growth and the higher a person's cognitive development, the less their anxiety spills over into social interaction. However, one person always influences and is influenced by the opioid / arousal of another and when internal mechanisms fail there is pressure to reassert attachment behaviours.

The human body, then, requires interaction with others to regulate itself. This supports the emphasis that Foulkes, Elias and Mead place on social processes of attachmentseparation, belonging and communicative interaction. It also supports those psychoanalysts, notably Winnicott, Fairbairn, Balint and Bowlby, who have placed so much importance on attachment behaviour.

\section{The Inseparability of Affect and Cognition}

A sharp distinction is often made between cognition, intellectual activity and rational decision making, on the one hand, and emotionally charged behaviour, on the other. Rational thinking is thought to be disrupted by the feelings and emotions that are inevitably aroused in personal relationships in groups. However, this separation between cognition and affect is challenged by Damasio's (1994) studies. He has found that severe damage to certain areas of the brain leads to a profound change in behaviour.

When particular areas of the brain are damaged, perfectly competent, normally functioning people lose the capacity to make rational, ethical choices and also the capacity to experience emotional variability. Damasio concludes that the damaged brain subsystems are the primary areas dealing with both rational, ethical decision making and emotional experience. The rational and the emotional are physiologically intertwined and the one cannot arise without the other, except in the most restricted of situations. Damasio points out how people suffering from this particular form of brain damage may well continue to function very well at an intellectual level in the sense that they can rationally generate sensible ranges of options for action. In simple laboratory situations they may even be able to take the next step and make rational decisions about which option to act upon. However, in the uncertainty and complexity of ordinary, every-day life they may continue to generate rational options for action but prove incapable of selecting and acting upon an option that is sensible in the circumstance. They display no emotion and at the same time they are incapable of acting either ethically or rationally, in their own best interests.

Damasio concludes that emotionally flat experience makes rational choice impossible and he suggests that this connection between feelings and rational / ethical choice is not a chance one. He argues that feelings are an essential part of the process of selecting actions that are sensible in the circumstances. Feelings orient the decision-maker in a useful direction, acting as a means of screening out some options when they do not 'feel right'. 
Damasio goes on to propose that the brain continuously monitors and integrates the rhythmical activity of the heart, lungs, gut, muscles and other organs, as well as the immune, visceral and other systems in the body. At each moment, then, the brain is registering the internal state of the body and Damasio argues that these body states constitute background feelings. This continuous monitoring activity, that is, registration of feeling states, is taking place as a person selectively perceives external objects, such as a face or an aroma, and experience then forms an association between the two. Every perception of an object outside the body is associated, through acting into the world, with particular body states or background patterns of feeling. So, when a person encounters situations similar to previous ones, he or she experiences similar feeling states, or body rhythms, which orient that person to act into the situation. In this way, human worlds become affect laden and feeling states unconsciously narrow down the options to be considered in a situation. In other words, feelings unconsciously guide choice and when the capacity to feel is damaged so is the capacity to rapidly select sensible action options. Damasio suggests that, from a neurological standpoint, the body's monitoring of its own rhythmic patterns is both the ground for its construction of the world it acts into and its unique sense of subjectivity.

Damasio holds that mind arises when bodies interact with each other and that changes in body rhythms continually affect mental states and the sense of self. It is not a great step to suggest that when people are relating to each other, in the presence of each other, their body rhythms might resonate with each other. An intuitive sense of how another is feeling could well be conveyed in this way. A process of resonance, rather than any form of transmission or mimicry, might then be the basis of empathy between people. Damasio (1999) also suggests that human bodies construct consciousness and knowledge in interaction with each other in a process in which the biological correlates of this activity take a narrative-like form. Damasio says that consciousness is a process of the brain constructing an account, or narrative, of what happens within the organism when it interacts with an object. He suggests that humans become conscious, they develop a feeling of knowing, when their bodies construct and present a 'specific kind of wordless knowledge' to do with being changed by contact with others.

\section{The Social Phenomena of Consciousness and Self-consciousness}

It is interesting to note how consistent are Damasio's conclusions, derived from modern brain research, with Hegel's philosophy of the knowing subject. Hegel held that one cannot begin, as Kant had done, with an isolated individual subject experiencing the world and then ask how a world of experience gets built up out of the inner world of purely subjective experience. Rather, one must begin with an already shared world of subjects making judgements in the light of possible judgments by others. Hegel accorded central importance to recognition, linking it to desire, particularly the desire for desire of the other. It is through mutual recognition that individuals sustain patterns of entitlements and commitments, the social, and it is in the social that the knowing subject, mind, emerges. Hegel emphasised the historical specificity of human self-conceptions upon which society is founded. Person and subject are given content only by the social 
institutions in which each individual achieves social identity through interdependence and mutual recognition. So, for Hegel, mind or consciousness is manifested in social institutions, that is, ways of life, which give identities, self concepts, to individuals.

Mead (1934), argued in the tradition of Hegel that human societies are not possible without human minds and human minds are not possible without human societies. For him, the fundamental unit of analysis was the social act. He defined the social act as a gesture by one person that calls forth a response from another, which together constitute meaning for both. Immediately, knowing becomes a property of interaction, or relationship. For example, one person smiles and this may call forth a counter smile, which means friendship; or the gesture could call forth a cold stare, which means hostility. Meaning, therefore, does not lie in the gesture alone but in the social act as a whole. Meaning does not arise first in each individual, to be subsequently expressed in action, nor is it transmitted from one individual to another.

For Mead, mind, or consciousness, meant awareness of what one was doing in relation to others. In the above example, the person smiling may not be aware of the likely responses to her gesture and the responder also may not be aware of the likely response to his response. There is still meaning but the communication is unconscious in that one or both of the parties do not know what they are doing in terms of possible outcome. Consciousness arises when we gesture to others in a manner that is capable of calling forth in ourselves the same range of responses (feelings and ideas) as in those to whom we are gesturing. This would happen if, for example, the smile of one called forth in herself the fleeting feelings associated with friendship and hostility, just as it did in the one to whom the gesture was being made. Mead described such a gesture as a significant symbol. If, when one makes a gesture to another, one is able to experience in one's own body a similar response to that which the gesture provokes in another body, then one can 'know' what one is doing. Possessing this capacity, the maker of a gesture can intuit, perhaps even predict, the consequences of that gesture. The whole social act, that is, meaning, can then be experienced in advance of carrying out the whole act, opening up the possibility of reflection and choice in making a gesture in a kind of private role-play, emerging in the repeated experience of public interaction. In this way, one individual learns to take the attitude of the other, enabling a kind of trial run in advance of actually completing or even starting the gesture. The first part of a gesture can be taken by the other as an indication of how further parts of the gesture will unfold from the response. In this way, the two can indicate to each other how they might respond to each other in the continuous circle in which a gesture by one calls forth a response from another, which is itself a gesture back to the first.

Mead then argued that the gesture that is particularly useful in calling forth the same attitude in oneself as in the other is the vocal gesture. This is because we can hear the sounds we make in much the same way as others hear them, while we cannot see the facial gestures we make as others see them, for example. The development of more sophisticated patterns of vocal gesturing, that is, of the language form of significant symbols, is thus of major importance in the development of consciousness and of sophisticated forms of society. Mind and society emerge together in the medium of 
language. However, since speaking and listening are actions of bodies, and since bodies are never without feelings, the medium of language is also always the medium of feelings. Mind, or consciousness, is the gesturing and responding action of a body directed towards itself as private role-play and silent conversation, and society is the gesturing and responding actions of bodies directed towards each other. They are thus the same kind of process.

Mead takes his argument further when he suggests how the private role-play evolves in increasingly complex ways. As more and more interactions are experienced with others, more roles and wider ranges of possible responses enter into the role-playing activity that is continuously intertwined with public gesturing and responding. In this way, the capacity to take the attitude of many others develops and this becomes generalized. Each engaged in the conversation of gestures can now take the attitude of what Mead calls the generalized other, which is the group and society. In every interaction between individuals, therefore, they are not simply taking the attitude of each other but at the same time they are taking the attitude of the wider society.

Self-consciousness is the capacity as subject to take oneself as object to oneself. In other words, it is the capacity to take the attitude of others not just towards one's gestures but also towards one as a self. The 'me' is the configuration of the gestures of the others / society to one as a subject, or an 'I'. As a subject, 'I', one has the capacity to be an object to oneself, a 'me'. A self, as the relationship between 'me' and 'I', therefore emerges in the social act, as well as an awareness of that self, that is, self-consciousness. In this interaction, the ' $\mathrm{I}$ ' is the response to the gesture of the group / society to oneself, that is, the 'me'. The 'me' is the perceived attitude of others to the ' $\mathrm{I}$ ' and the ' $\mathrm{I}$ ' is the response. Mead argues, very importantly, that the 'I' response to the 'me' is not a given but is always potentially spontaneous and hence unpredictable.

The symbolic processes of mind / self are always actions, experienced within a body as rhythmic variations, that is, feeling states. Mind is the action of the body, rather like walking is the action of the body. One would not talk about walking emerging from the body and it is no more appropriate to talk about mind emerging from the brain (Elias, 1991). Note how the private role-play, including the silent conversation of mind / self, is not stored as representations of a pre-given reality. It is rather, continuous spontaneous action in which patterns of action are continuously reproduced in repetitive forms as continuity, sameness and identity, and simultaneously as potential transformation of that identity. In other words, as with interaction between bodies, the social, so with interaction of a body with itself, mind, there is the experience of both familiar repetition of habit and the potential for spontaneous change.

Now consider the patterning effect of the 'conversation of gestures'. Each party to an interaction has a history of experience. That history has patterned the private role playing of each individual in particular ways that enact, that is selectively enable and constrain, what that individual responds to both privately and publicly. That history establishes what aspects of the gesturing of the other will be striking, will call forth, or evoke, a response and what kind of response it will evoke. This intertwining of enactment and 
evocation is made possible, and at the same time limited, by previous history. And the histories of the groups people are part of also become relevant. Those collective and individual histories, reproduced in the living present of communicative action, are extending those histories into the future. This points to the narrative-like structuring of human experience. The turn-taking, responsive relating of people may be thought of as forming narratives at the same time as those narratives pattern moral responsibility. It is in the micro interaction of their turn-taking conversations that people are perpetually constructing the living present and thus the future. This perpetual construction has the paradoxical characteristics of repetition and transformation at the same time. And what is being constructed is nothing less than the individual and collective identities of those involved, identities always open to potential transformation.

Each individual is simultaneously evoking and provoking responses from others so that the particular personal organizing themes emerging for any one of them will depend as much on the others as on the individual concerned. Put like this, it becomes clear that no one individual can be organizing his or her experience in isolation because they are all simultaneously evoking and provoking responses in each other. Together they immediately constitute complex responsive processes of a recursive, reflexive, selfreferential kind. And as they do so, themes emerge that organize their experience of being together out of which further themes continuously emerge. Both mind and the social can then be thought of as continuously replicating patterns of themes and variations that organize the experience of being together (Stern, 1985, 1995; Stolorow, Attwood \& Brandschaft, 1994).

\section{Unconsciousness as Social Processes}

A person can communicate with another in a direct way in which the gesture of one does not call forth in himself the same response as in the one gestured to. They may be communicating meaningfully with each other but not in significant symbols which means that they are not conscious in the sense of calling forth in themselves the same responses as in the others. For example, the intricate conversation of gestures between infant and mother described by Stern (1985) is largely unconscious in this sense. Another example is when adults unconsciously communicate how they feel to each other. This is the basis of intuitive communication between people and it is one important sense in which communicative and power relating, that is social, processes are unconscious.

People also communicate with each other in the medium of significant symbols, where the gesture of one does calls forth in herself similar responses to those called forth in the other. However, this is a potential, not an automatic guarantee. So, some processes of communication in the medium of significant symbols may be unconscious in the sense that the gesturer is not realising the potential for knowing, that is, not paying attention to the responses that one's gesture is calling forth in oneself. For example, I might say something to another that provokes a hurt response. On reflection I realise that I did have some feeling that this might happen but simply paid no attention to it. Since I did not 
intend to hurt I would not have chosen to carry out the gesture if I had paid attention. This is another aspect of what I mean by unconscious processes. It takes the form of communication between people where the meaning of the communication is not formulated or articulated to themselves. There is some similarity to what I am saying here with the work of the relational psychoanalyst, Donnel Stern (1983; 1997), who has developed the notion of the unformulated unconscious and the intersubjective psychoanalysts, Robert Stolorow and colleagues (1994), who have developed the notion of the unvalidated unconscious.

Briefly, unformulated communication consists of vague tendencies, which are potentially articulable if allowed to develop. Here clarity and differentiation of meaning are not yet known in terms of language. Such communication is a beginning of insight not yet formulated and conscious communication is constructed as progressive articulation of this unformulated and hence unconscious communication. Unformulated communication is communication not yet consciously grasped and Stern regards it as creative disorder from which the new emerges. Unvalidated communication is also communication that is not articulated but not because it is not yet formulated. The communication is not articulated because a history of the absence of validating responses has meant that it never could be articulated. This occurs because a lack of attunement, or some traumatic event, usually in childhood, makes it impossible, pointless, or highly dangerous to articulate a particular communication. Neglect, futility and the danger of traumatisation prevent articulation. Unformulated and unvalidated communication is another sense in which we can talk about unconscious processes.

Yet another sense in which communicative interaction may take the form of unconscious processes is as follows. Communication in the sense of gesture-response that takes place in significant symbols, and which is formulated and articulated, can become habitual and so easily repeated automatically. In this sense communicative interaction becomes unconscious. This is communication that was once formulated, validated and articulated but its meaning is now so taken for granted that those communicating are unconscious of it. The meaning of unconscious processes that I am referring to here is not necessarily that of some active form of repression. It may simply be a consequence of skilled behaviour. This notion of unconscious process draws on Stolorow and colleagues (1994) who propose the notion of a pre-reflective unconscious, which is recurring patterns of communication that become invariant principles unconsciously organising subsequent experience. As an example, they point to organising principles that derive from a child's perception of what is required of him/her to maintain ties that are vital to his/her wellbeing. Some communication may once have been formulated and recognised in the response, being in that sense validated, but the response might have been experienced as hostile or dangerous. Such a pattern of communicative interaction is then repeatedly blocked from consciousness in a manner that might be described as repression. This is similar to Stolorow's formulation of the dynamic unconscious in which particular themes are prevented from crystallising into consciousness because they are associated with danger, particularly the danger of threatening current configurations of interaction that allow people to cope. 
There are a number of points to notice about the notions of unconscious communication described above. First, each of the patterns of unconscious communication distinguished is an aspect of processes of communicative interaction and power relating and they cannot be separated from each other. They are simultaneously occurring aspects of social processes not separate types that can be experienced separately in some pure form. Second, there is no boundary between conscious and unconscious communication because they are aspects of temporal processes of communication, not spatial concepts located anywhere. Third, conscious and unconscious communications apply simultaneously to interaction between bodies, the social, and the interaction of each body with itself, mind. Meaning is at the same time conscious and unconscious, individual and social.

The unconscious communication described above is social in the sense that it has to do with interaction between people and they always take place in a wider social context. Elias (1939/2000) talks about the automatic (hence unconscious), self-compulsive nature of self-control instilled in individuals brought up in the kind of society that has evolved in the West, in which so much is banished behind the scenes. Processes of shame, humiliation, repugnance and disgust play a major role in this instillation of self-control and they are all simultaneously individual and social. The particular kind of society people in the West live in requires that people conduct themselves in particular ways and their compliance is assured by particular kinds of personality and mental process, that is, particular ways in which people experience themselves. In other words, particular forms of society require particular kinds of 'we' and 'I' identities. All of this relies on processes of shame to sustain the particular kinds of self-restraint required by Western society at this time. In other times and in other places, social patterns and the way people experience themselves, their 'we' and 'I' identities, are all different and processes of shame and humiliation are patterned in different ways.

In their discussion of power relations, Elias and Scotson (199/1965) point to how people form groups in processes of inclusion and exclusion. It is from these groups that they derive their 'We' identities. The power balance between groups is sustained by ideology and people are unconscious of this process (Dalal, 1998, 2001). Such ideologies tend to ascribe charisma to one group and stigma to another. The impact of charisma on one group and stigmatisation on another and how this is tied up with the evolution of 'we' and 'I' identities are all processes that are largely unconscious. The consequent habitus or way of life, which is both social and individual at the same time, is unconscious and so is the role of ideology in sustaining power relations, as is the shifting dynamic of inclusion and exclusion that accompanies it. The same applies to that constellation of processes to do with shame, anxiety, inclusion-exclusion, panic and aggression. Throughout, these unconscious processes are simultaneously individual and social as is conscious communicative interaction and power relating. Another way of putting it is to say that we are often not of the 'me' in our self consciousness or of the generalised other in our interaction with others. We are not be conscious of many of the themes organising our experience of being together. Just as we are not conscious of fantasy elaboration in our private role play / silent conversation. 
Just as processes of conscious communication have singular (individual) and plural (social) aspects, so too do processes of unconscious communication. Unconscious processes of communication and power relating take the singular aspect in the form of the private role play of an individual of which that individual is not aware. Unconscious processes of communication and power relating take the plural aspect in the form of public interaction between people of which they are not aware. Singular and plural, conscious and unconscious, processes are inextricably intertwined and considering them separately is an abstraction from the actual experience of relating.

I am suggesting, then, a way of thinking about that which is unconscious in terms of communicative interacting and power relating between people and this is a completely different notion to any idea of intrapsychic mechanisms, or "the unconscious". Psychoanalytic theories of the mind are built on the assumption that the mind is an internal world of representations and "the unconscious" is an agency in that internal world operating as an efficient cause of individual human actions. According to this view an individual does what she does because of instinctual wishes and modes of repressing and defending against them understood as the dynamic unconscious. Or an individual does what he does because of universal, inherited fantasies of aggression and persecution and mechanisms of splitting, introjection and projection, all of which are unconscious. The theory of complex responsive processes presents a very different notion of unconscious processes.

Having looked at normal consciousness and unconsciousness what does disturbance or pathology consist of?

\section{Disturbance and Pathology: Distortions and Failures of Communication}

'Normal' communication occurs when people are able to go on satisfactorily enough with each other with good enough feelings of well being. This occurs when each person in the group is taking the attitude of the others that he or she is in immediate interaction with and at the same time taking the attitude of the group / society towards his or her actions and self. This normal process of communicative interaction and power relating is both conscious and unconscious at the same time. We can understand disturbance as the distortion of communication and power relations in either or both of their conscious and unconscious aspects, such that people have extreme difficulty in going on together with good enough feelings of well being. Such distortion threatens necessary attachment and separation patterns, as well patterns of inclusion and exclusion, and so threatens identity in both its individual and collective aspects at the same time. This raises anxiety levels and triggers processes of shame, which could further distort communication in a vicious circle. It is in this sense that we might say that distorted communication is pathological. Certainly this was the view of Foulkes $(1948,1964)$. Pathology might be defined as failure to take the attitude of others and failure to take the attitude of the group / society. The result can be seen in oppressive power relations, which may well be taken up in peoples' private role plays and directed towards themselves. Disturbance thus amounts to 
a lack of spontaneity and a diminution of the capacity to adapt and transform so that those involved cannot go on together in a reasonably effective manner, with a reasonable sense of well being.

Complex responsive process of shame and guilt, patterned as social and individual experience, not only sustain patterns of society but simultaneously lead to all manner of emergent difficulties. Shame is closely intertwined with processes of inclusion-exclusion and so attachment-separation. These processes are linked to anxiety and fear and also the fear of the fear, which is panic. And panic, which is a bodily experience of waiting for unconsciously feared shaming breaks in attachment, often further increases the shame itself and the breaks in attachment (Aram, 2001). This whole constellation of social / individual processes easily triggers aggression and violence. This may take the form of envious attacks that destroy the attachment bonds of others, where some try to spoil what others have because they want it but cannot have it. Or the attacks may arise from threat to 'we' identities when it is felt that beliefs and actions in another group threaten the way of life of one's own group. Paradoxically, then, the very processes required to sustain Western society are also process highly destructive of it.

Notice how we are talking about distortion, disturbance, and pathology as simultaneously individual and social rather than as an intrapsychic process. This raises the question of how one might understand, from a complex responsive processes perspective, the classical psychoanalytic notions of distortion in communication, namely, transference, projection, and projective identification. The complex responsive processes perspective I have been outlining above is one that focuses on interaction as temporal process. It makes no use of the spatial metaphors of mind inside a person and society outside. It is an action theory of knowing that does not make use of notions of internal representations and transmission of ideas or contents from one person to another. The terms transference, projection, and projective identification are thus difficult to use in this context because they imply transmission from one to another. However, they are pointing to important forms of distortion which can be translated into Mead's terminology.

Transference could be understood in the following way. A gestures to $\mathrm{B}$ taking the attitude of $C$ (a figure in his past) rather than that of B. One might say that A mistakes B for $\mathrm{C}$ and is not conscious of doing so. $\mathrm{B}$ may then respond to the current reality of A's gesture, most probably in a way not expected by $\mathrm{A}$, and so the communication is distorted. It could be even further distorted if B responds in a way often experienced in previous relations with $\mathrm{D}$ (countertransference). Or, in her private role play of, or reflection on, A's gesture and her countertransference, she may understand the nature of the confusion and respond in a way that demonstrates some understanding of A's gesture. This could shift the communication from its stuck pattern. However, from a complex responsive process perspective, $\mathrm{A}$ and $\mathrm{B}$ will always be communicating in a way that is simultaneously selected by the past experience of each and called forth by each other's responses. We are always iterating and constructing reality in this way and the potential for the transformation of repetitive patterns lies in the spontaneous amplification of small differences from one present to the next. Transference and countertransference then lose their special meanings and come to be particularly repetitive themes having very little 
scope for amplification into some new pattern of relating, unless the parties can understand what is happening. We will always be iterating themes from our past but when we do so in very rigid ways, communication becomes stuck in repetitive patterns that are not understood because they are unconscious. The resulting distortion of communication can be very distressing and the concepts of transference and countertransference are drawing attention to this possibility.

In psychoanalytic theory, projection is understood as the evacuation of unwanted mental contents from one's the internal world onto another person who is outside, mistaking that other for an unwanted aspect of oneself in the process. This could be translated into gesture-response terms as follows. A experiences certain feelings but his private role play, patterned by his past experience, is such that it defensively blocks his awareness of the feelings. So as he gestures to $\mathrm{B}$, he takes the attitude, not of the other, but of himself, confusing this with attitude of B. In other words, instead of A calling forth a similar response to that of $\mathrm{B}$, he calls forth a response that has to do with habitual / imagined themes in his own private role play / silent conversation. In this way the communication is distorted. The notion of projective identification takes this potential for distortion a step further. In psychoanalytic theory, projective identification is understood as a process in which one person puts unwanted feelings into another who then feels them as his or her own, while the first has the fantasy of controlling the other from within. In gesture response terms one might understand this is follows. A gestures to $\mathrm{B}$, taking the attitude of his own past rather than that of B as in the case of projection just described. B may not understand this and in responding takes the attitude that $\mathrm{A}$ is unconsciously denying. For example, A may say something aggressive to B while consciously holding that he is not being aggressive. $\mathrm{B}$ may well then respond in a very aggressive way. A may then not understand this and so a vicious circle of distorted communication is triggered. Or, B may recognise that the feeling being evoked in her has more to do with A's private role play than with her own. In her response she might be able to take up this more complicated attitude of $\mathrm{A}$ and so possibly evoke a more aware response form $\mathrm{A}$.

However, the interaction between A an B will always be much more complex than the descriptions I have just given in the cases of transference / countertransference, projection and projective identification. This is because both A and B will always be simultaneously taking the attitude of various groups they belong to, almost always unconsciously. For example, A and B may both belong to the same society but A might be an engineer while $B$ is a psychotherapist. To some extent they will be taking the attitude of the same group, their society, but they will also be taking the attitude of different groups at the same time. A may take the attitude of the engineering community while B takes the attitude of the psychoanalytic community. The potential for distortion is magnified. For example, B, in taking the psychoanalytic attitude focuses on transference and countertransference, projection, projective identification as the meaning of their communication, understanding them as intrapsychic phenomena and so missing out on the wider social themes and power relations being enacted.

So while psychoanalytic theory and the theory of complex responsive processes are concerned with the same kind of distortion of communication, they provide rather 
different explanations. In psychoanalytic theory, the origin of the miscommunication lies in intrapsychic mechanisms. There is an implication of unconscious intent and of "the" individual unconscious as agent. From a complex responsive process perspective, the explanation of distorted communication is a social one. The explanation is given in terms of the habitual thematic patterning of interaction arising in histories of relating and always implicating wider social groupings. There is no notion of individual unconscious intent. Instead patterns emerge in the self organising, habitual interaction between people that always have the potential for spontaneity and transformation. From a complex responsive process point of view, there is no putting of feelings into each other but the phenomenon projective identification is getting at could be understood as direct communication in the form of the resonance of one person's body rhythms with those of another.

The perspective of complex responsive processes focuses attention on conversational processes. Some conversational processes display the dynamics of stability when patterned by habitual, highly repetitive themes. In this dynamic, people are "stuck" and their conversation loses the potential for transformation. Identity arising in "stuck" conversation is continuity with little variation. One might characterize such conversational dynamics as neurotic. The quality is lifeless, depressing, even obsessive and compulsive. Other conversational processes display the dynamics of instability in which coherent pattern is lost as fragments of conversation trigger other fragments with little thematic structure. One might characterize such conversation as disintegrative, approaching the psychotic. The quality is manic confusion and distress with a fragmenting of identity. Yet other conversational processes display a dynamic, where patterning themes have the paradoxical characteristics of continuity and spontaneity at the same time. The felt qualities of such conversations are liveliness, fluidity and energy but also a feeling of grasping at meaning and coherence. There is excitement but also, at the same time, tension and anxiety. When conversational processes are characterized by this kind of dynamic, they have the potential for transformation. For example, in describing the quality of therapeutic conversation, Foulkes $(1948,1964)$ referred to "free floating conversation" and he contrasted this with the location of neurotic symptoms in individual members of a group which lead to stereotypical patterns of conversation that have no therapeutic, that is, transformational potential.

\section{Conclusion}

This paper has argued for a way of that which is unconscious in human action that moves from the individual centred notion of 'the unconscious' found in psychoanalytic theory to a notion of unconscious processes as social phenomena. The latter perspective represents a theory of complex responsive processes based upon the thought of Mead and Elias. Instead of an individual agency located as 'the' unconscious, unconscious processes refer to those aspect of human communicative interaction and power relating that are emerging as patterns in that very relating. The cause of the patterning of human interaction, simultaneously conscious and unconscious does not lies in some individual agency 
abstracted from the experience of interaction. The cause of the patterning of interaction is the interaction itself.

\section{References}

Aram E. (2001) The Experience of Complexity: Learning as the potential transformation of identity, unpublished thesis: University of Hertfordshire.

Dalal, F. (1998) Taking the Group Seriously: toward a post Foulkesian group analytic theory, London: Jessica Kingsley.

Dalal, F. (2001) The social unconscious: a post-Foulkesian perspective, Group Analysis, 4, 34, pp539-557.

Damasio, A. R. (1994), Descartes’ Error: Emotion, reason and the human brain, London; Picador.

Damasio, A. R. (1999) The Feeling of What Happens: Body and emotion in the making of consciousness, London: Heinemann.

Elias, N. (2000/1939) The Civilizing Process, Oxford: Blackwell.

Elias, N. (1991) The Society of Individuals, Oxford: Blackwell

Elias, N. \& Scotson, J. L. (1994/1965) The Established and the Outsiders, London: Sage.

Foulkes, S. H. (1948), Introduction to Group Analytic Psychotherapy, London: William Heinemann Medical Books Limited

Foulkes, S. H. (1964), Therapeutic Group Analysis, London: George Allen \& Unwin.

McGuire, M. T., Raleigh, M. J., \& Brammer, G. T. (1984) Adaptation, selection, and benefit-cost balances, Ethology and Social Biology, 5:269-277.

Mead, G. H. (1934), Mind Self and Society, Chicago: Chicago University Press.

Reite, N. \& Field, T. (1985) The Psychobiology of Attachment and Separation, Orlando, Florida: Academic press.

Schore, A. N. (1994) Affect Regulation and the Origin of the Self: the neurobiology of emotional development, Hillsdale NJ: Lawrence Earlbaum Associate Inc.

Siegel, D. J. (19999) The Developing Mind: toward a neurobiology of interpersonal experience, New York: The Guildford Press. 
Smith, T. S. \& Stevens, G. T. (1999) The architecture of small networks : strong interaction and dynamic organization in small social systems, American Sociological Review, Vol 64, June, 403-420.

Smith, T. S. (20001) Hyperstructures: Strong interaction and the biological structure of social life, unpublished manuscript.

Stacey, R., Griffin \& Shaw (2000) Complexity and Management: Fad or radical challenge to systems thinking? London: Routledge.

Stacey, R. (2003) Complex and Group Processes: A radically social understanding of the individual, London: Routledge.

Stern, D. N. (1985) The Interpersonal World of the Infant, New York: Basic Books

Stern, D. (1983) Unformulated experience: from familiar chaos to creative disorder, Contemporary Psychoanalysis 19(1): 71-99, reproduced in Mitchell, S. A. \& Aron, L. eds. (1999) Relational Psychoanalysis: The emergence of a tradition, Hillsdale NJ: The Analytic Press

Stolorow, R., Atwood, G. \& Brandchaft, B. (1994) The Intersubjective Perspective, Northvale, NJ: Jason Aaronson.

Wise, R. A. \& Rompre, P. (1989) Brain dopamine and reward, Annual Review of Psychology, 40: 191-225. 